\title{
EMPERIPOLESIS: STERNAL AND FEMORAL MICROENVIRONMENT INDUCES MEGAKARYIOCYTE EMPERIPOLESIS IN THE WISTAR STRAIN
}

\author{
Damir Suljević, Filip Filipić, Erna Islamagić \\ Department for Biology, Faculty of Science, University of Sarajevo, \\ Zmaja od Bosne 33-35, 71000 Sarajevo, Bosnia and Herzegovina
}

Received 18 January 2018; Received in revised form 2 June 2018; Accepted 4 July 2018

\begin{abstract}
Emperipolesis is considered a physiological phenomena often present in various pathophysiological conditions, but its etiology is still unknown. In this study, we analyzed the number of megakaryocytes and the percentage of emperipoletic cells in the sternal and femoral bone marrow of Wistar rats. Five types in the thrombopoiesis lineage (megakaryoblasts, promegakaryocytes and megakaryocytes - acidophilic, basophilic and thrombocytogenic) were determined. Except for basophilic megakaryocytes, significant differences were found for number of thrombopoietic cells in the sternal and femoral bone marrow. A larger number of thrombocytogenic megakaryocytes were present in the sternal bone marrow. Emperipoletic cells were significantly present in the femoral compared to the sternal bone marrow. Emperipolesis was typical for lymphocytes and neutrophils individually, while emperipolesis with two or more cells within thrombopoietic cell was also present (1-7 \%) and significant differences between the sternal and femoral bone marrow were detected. Emperipolesis was found in all analysed rats and it most commonly occured within mature megakaryocytes and rarely megakaryoblasts, while it was not recorded in the promegakaryocytes. The high incidence of megakaryocytes with emperopolesis in rats could be a consequence of "normal" cell retention in the cytoplasm of megakaryocytes while passing blood cells to circulation or related to haematopoietic response due to high incidence of inbreeding.
\end{abstract}

Key words: bone marrow, emperipolesis, femur, megakaryocytes, Wistar strain

\section{INTRODUCTION}

The recent research data associated with the phenomena like engulfment of one cell into another, include processes such as emperipolesis, entosis and cell cannibalism. All these phenomena are closely related (cell-in-cell phenomenon), yet they differ from one another. Analysing the mentioned phenomena is quite important as they play a major role in the establishment of diagnostic and prognostic values (1). Emperipolesis is a type of cell engulfment where the cytoplasm of a host hematopoietic cells contains other cells, most

Corresponding author: Prof. Damir Suljević, $\mathrm{PhD}$

E-mail address: suljevic.damir@gmail.com

Present address: Department for Biology, Faculty of Science,

University of Sarajevo, Zmaja od Bosne 33-35, 71000 Sarajevo,

Bosnia and Herzegovina

Phone: +0038733723756

Copyright: (C) 2019 Suljević D. This is an open-access article published under the terms of the Creative Commons Attribution License which permits unrestricted use, distribution, and reproduction in any medium, provided the original author and source are credited.

Competing Interests: The authors have declared that no competing interests exist.

Available Online First: 4 February 2019

Published on: 15 March 2019

https://doi.org/10.2478/macvetrev-2019-0012 often neutrophils, lymphocytes and plasma cells in aliving and intact state. The most common host cells are megacaryocytes, histiocytes, monocytes, endothelial cells, lymphocytes and plasma cells (2). In this phenomenon both cells are sustainable without apparent morphological and physiological consequences for the "engulfed" cell and host cell (3). This phenomenon is different from phagocytosis, because the affected cell within the host cell remains viable and leaves the cell without physiological and morphological consequences. This process can be physiological or pathological like a pathognomonic feature of some diseases (4). Ethiopathogenesis is undefined, especially in hematolymphoid disorders and some non-hematological malignant diseases in humans (3). Emperipolesis has been established in bone marrow aspirates, liquors, and tissue cultures in some diseases (5). Histiocytes have shown emperipolesis of lymphocytes, plasma cells, neutrophils and erythrocytes in RosaiDorfman disease (6). Megacaryocytic bone marrow emperipolesis increases due to granulocytic or erythropoietic hyperplasia. Otherwise, the presence 
of emperipolesis in erythroblasts was increased during high erythropoietic activity in the liver and relative fetal anemia (7). The megacaryocytic emperipolesis in bone marrow was found in some cases of chronic lymphatic leukemia and hairy cell leukemia (8). Emperipolesis nowadays is understood as a mechanism for improving of cell survival and preventing cell apoptosis within the host cell or control cells that may be cytotoxic to the host cells (7). Emperipolesis presented in lymphoma is related with the role of cytokines release from lymphoma cells, which may be the result of active adherence of lymphocytes to tumor cells or macrophages (9). Some studies showed that emperipolesis is the pathway which is mediated by natural killer cell-mediated tumor cell death, where the target cell membrane fluidity is essential for this interaction (10). "Suicidal emperipolesis" is the most recently reported process, which is taking place in a non-malignant environment. It is the first cell-in-cell structure described having a role in maintaining homeostasis in organism (11).

The aim of this study was to analyze the number of megakaryocytes in the bone marrow of the femur and sternum of Wistar rats and to determine the presence and percentage of emperipolesis within megakaryocytes. A special task was to determine the most common type of cells affected by emperipolesis.

\section{MATERIAL AND METHODS}

\section{Animal Breeding}

In this experimental design, we used 10 individual rats (Rattus norvegicus, Wistar strain). Animals were bred in the Laboratory for Biochemistry and Physiology, Faculty of Science, Sarajevo. The animals were kept in special cages at an optimum room temperature $\left(25^{\circ} \mathrm{C}\right)$ and fed with the Oxbow Essential pellets for rats with water ad libitum. During the breeding and experimental phases animals were treated according to the ethical and legal requirements ("Declaration on the Rights of Animals", UNESCO 1978 and "Universal Declaration on Animal Welfare”, WSPA 2000).

\section{Experimental design}

The selected animals used in this study were 15 weeks old with a mass between $250 \mathrm{~g}$ and 290 g. Sufentanil $/$ medetominide $(50 / 150 \mu \mathrm{g} / \mathrm{kg})$ was used for anesthesia and a doubling dose was administered intramuscularly for euthanasia. After euthanasia, the femur and sternum were completely isolated and used for further bone marrow isolation and analysis. Both bones were longitudinally cut and the bone marrow was removed with a small gauge needle (22G; Semikem, Sarajevo, $\mathrm{BiH})$. The bone marrow was placed on a microscop slide and smeared gently using the touch technique. The smears were stained by May-Grünwald and Giemsa stains (Sigma-Aldrich).

\section{Microscopic analysis}

Cell identifications were performed on an Olympus BX41 light microscope and an Olympus DP12 camera. Image analysis and processing was done in the licensed software (Olympus DP12 Soft DP12-CB Ver.01.01.01.42. ® Olympus Corp).

\section{Statistical analysis}

The obtained results were analyzed using the IBM SPSS ver. 20 statistical software (Inc., Chicago, IL, USA). For all data, the mean, standard deviation and range were calculated. One way ANOVA was used to calculate significant differences ( $\mathrm{p}$ value less than 0.05 shows significant differences).

\section{RESULTS}

Table 1. shows the percentage of megakaryocytes, including standard deviation and range, in the femoral and sternal bone marrow. In the femoral bone marrow, a larger number of megakaryoblasts, promegakaryocytes, acidophilic and basophilic megakaryocytes were present in relation to the sternal bone marrow. Otherwise, the sternal bone marrow contained a significantly higher number of thrombocytogenic megakaryocytes. Only for the acidophilic and basophilic megakaryocytes significant differences between the sternal and femoral bone marrow were not found.

Table 2. shows the percentage of emperipoletic cells in the sternal and femoral bone marrow. The total number of emperipoletic cells was calculated to be 100 megakaryocytes in total. We found that incidence of emperipolesis was $10-30 \%$ in the femur and $12-26 \%$ in the sternum. In our study, emperipolesis mainly included one type of cell (most commonly lymphocytes) within megakaryocytic cell and it was rather more present in the sternum $(13.60 \pm 3.24)$ than in the femur $(10.90 \pm 4.70)$. The emperipolesis of neutrophils was more observed in the sternal bone marrow, while emperipolesis with more than two cells was significantly presented in the femoral bone marrow. 
Table 1. The percentage of megakaryocytes in the sternal and femoral bone marrow

\begin{tabular}{llllll}
\hline Bones & Femur & \multicolumn{3}{l}{ Sternum } \\
\hline Cells & Mean \pm stdv & Range & Mean \pm stdv & Range & Sig. \\
Megakaryoblasts \% & $5.40 \pm 1.58$ & $3-9$ & $4.00 \pm 0.94$ & $2-5$ & $0.013^{*}$ \\
Promegakaryocytes \% & $4.80 \pm 0.79$ & $4-6$ & $3.20 \pm 0.79$ & $2-4$ & $0.000^{*}$ \\
Acidofilic megakaryocytes \% & $39.10 \pm 8.32$ & $24-50$ & $36.90 \pm 6.17$ & $23-43$ & 0.255 \\
Basofilic megakaryocytes \% & $41.40 \pm 6.79$ & $31-52$ & $38.80 \pm 6.94$ & $29-54$ & 0.204 \\
Thrombocytogenic megakaryocytes \% & $9.30 \pm 3.20$ & $6-16$ & $17.10 \pm 5.63$ & $10-25$ & $0.001^{*}$ \\
\hline
\end{tabular}

Note: * significant values at 0.05

Table 2. Percental ratio of emperipoletic cells in the sternal and femoral bone marrow

\begin{tabular}{llllll}
\hline Emperipolesis & Femur & \multicolumn{3}{l}{ Sternum } \\
\hline & Mean \pm stdv & Range & Mean \pm stdv & Range & Sig. \\
\hline Emperipoletic cells \% & $16.90 \pm 5.78$ & $10-30$ & $20.40 \pm 4.03$ & $12-26$ & 0.067 \\
Emperipolesis of lymphocytes \% & $10.90 \pm 4.70$ & $4-21$ & $13.60 \pm 3.24$ & $8-18$ & 0.076 \\
Emperipolesis of neutrophiles \% & $3.13 \pm 1.81$ & $1-6$ & $4.30 \pm 1.77$ & $2-8$ & 0.092 \\
Emperipolesis of more cells \% & $3.89 \pm 1.83$ & $1-7$ & $2.50 \pm 1.08$ & $1-5$ & $0.029 *$ \\
\hline
\end{tabular}

Note: * significant values at 0.05
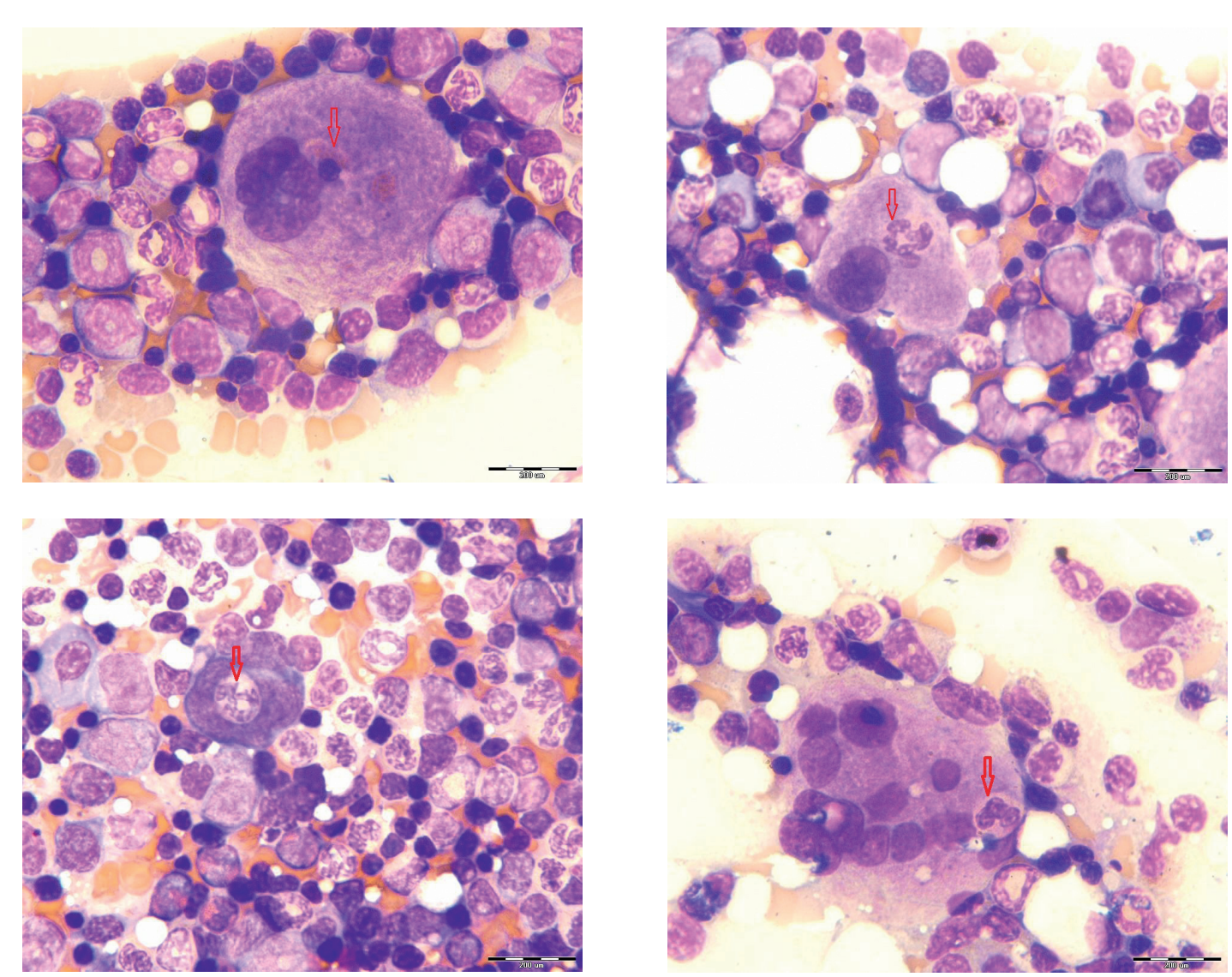

Figure 1. Emperipoletic cells in the bone marrow (a-emperipolesis of lymphocytes within megakariocyte; b-emperipolesis of neutrophiles within megakariocyte; c-emperipolesis of neutrophilic granulocyte within megakaryoblast; d-emperipolesis of more cells in megakariocyte; scale bar $=20 \mu \mathrm{m}$ ) 
Figure 1 shows megakaryocytes that engulf some cells of the leukopoietic lineage. Emperipolesis was most common in mature megakaryocytes. However, one example of emperipolesis was observed in the megakaryoblast, (Fig. 1c), as immature cells. Emperipolesis was not found in the promegakaryocytes.

\section{DISCUSSION}

In the femoral bone marrow of rats, a higher number of megakaryocytes were presented in comparison to the sternum. This may be due to the anatomical bone structure that contains a greater cavity and it is filled with larger amount of bone marrow. On the other hand, the sternum does not have a large bone cavity and contains a larger number of osteoclasts and osteoblasts participating in the ossification. Osteoclasts are very large cells, morphologically like megakaryocytes. Osteoclasts promote the formation of hematopoietic niches for stem cells in the bone marrow (12).

Considering the osteoclast function and the structure of the sternum, thrombopoiesis is probably poorly active in this microenvironment. However, maturation of thrombocytogenic megakaryocytes is significantly higher in the sternal bone marrow. We believe that such a bone structure leads to a higher production ofmegacaryocytic cells in the bone marrow and that the bone marrow sternum is responsible for the platelet maturation of thrombocytes produced by thrombocytogenic megakaryocytes, as the last mature cell of the thrombocytogenic line.

Recent studies regarding characterization of bone marrow structure and function reported the special microcircuits associated with the differentiation or mobilization of hematopoietic stem cells (13). The analysis of the cell composition and its localization identified a peri-vascular niche composed of endothelial, CXCL12+ reticular cells and nestin + mesengimal stromal cells, as well as an endosa-related niche composed of osteoblasts, osteolinage cells, and NG2+ pericytes (14). During the differentiation of hematopoietic stem cells, megakaryocytes migrate from the endost to the vascular niche where the platelets are directed into the bloodstream, as a end stage of maturation in the megakaryopoiesis. Megacaryocytes are closely linked to the vascular bone marrow niche, where they are found in adjacent sinusoids in the bone marrow using intravital fluorescence microscopy (15).

Ex vivo analysis of the localization of megakaryocytes showed that they are presented in various anatomical parts of the rat bone marrow that are interconnected with the endosteum, through arterioles and sinusoids (16). Megacaryocytes play a major role in the production of platelets through a highly controlled formation of long, branched protrusions known as protrombocytes connected with cytoplasmic bridges (17). Prothrombocytes pass through the sinusoids between endothelial cells; however signals that regulate the terminal maturation of megakaryocytes are still unknown. The presence of a large number of thrombocytogenic megakaryocytes in the sternal bone marrow is a point of interest.

Many in vitro and in vivo studies have shown a clear role for the megakaryocytes in modulating the proliferation and differentiation of osteoblasts and osteoclasts. In four models of mice megakaryocytosis and osteosclerosis were observed, indicating the positive effect of the megacaryocytic line on the cellular dynamics in the bone marrow (18). Megacaryocytes express osteoprotegerin (OPG), GM-CSF, RANKL and others that inhibit the development of osteoclasts, as well as some factors that enhance the proliferation and differentiation of osteoblasts. Therefore, often in the bones of the bone marrow, beside the megakaryocyte, osteoclasts are also presented.

In our study, emperipolesis has been established in all rats and there was no significant difference in their formation in the femoral and sternal bone marrow. Emperipolesis can affect all types of hematopoietic cells, most often a leukocyte lineage, although this phenomenon is often related to lymphocytes and neutrophil granulocytes. On the other hand, the megakaryocyte emperipolesis is mainly found in mature cells, although one case is observed in megakaryoblasts. This cell-in-cell phenomenon was not found for promegarkariocytes. The reason for the presence of emperipolesis in mature megakaryocytes is probably due to the fact that megakaryocytes have larger dimensions and higher free cytoplasmic space than megakaryoblasts. Megakaryoblasts and promegakaryocytes have a large nucleus and smaller cells, which makes this phenomenon often absent in immature form. The largest number of megakaryocytic emperipolesis involved one type of cell, a lymphocyte or neutrophil granulocyte.

Microscopic observation of affected hematopoietic cells (lymphocytes or neutrophils) by megakaryocytes did not show any morphological changes in the affected cell or the formation of phagosomes in megakaryocytes. Emperipolesis of megakaryocytes in the human bone marrow are 
present at various clinical conditions (19). According to Tavassoli (20), emperipolesis is related with blood loss and neutrophil emperipolesis have been increased in patients with autoimmune hemolytic anemia and iron deficiency.

Increased and pathologic emperipolesis of neutrophils within megakaryocytes is associated with marrow fibrosis (21). The incidence of megakaryocytic emperipolesis is significantly increased in rats during the aging process, where hematopoietic cellular hyperplasia in the bone marrow has been observed as the result of chronic blood loss and chronic inflammation (22). Otherwise, the incidence of emperipolesis in younger rats (2-12 months) was $0.3 \%$ and it was increased by $2-5 \%$ in the older rats (18-24 months). In a study performed by some authors (23) where incidence of megakaryocytic emperipolesis was analysed after X-ray exposure, the frequency of megakaryocytic emperipolesis was less than $15 \%$ of the megakaryocytes in control group but it increased to $34 \%$ in mice that had only been irradiated (23).

Our results are not in accordance with published studies, especially regarding the age of rats in whom emperopolesis was detected. In our study, the incidence of emperipolesis was $100 \%$ in young rats (15 weeks old). On the other hand, if emperipolysis can be considered as a physiological phenomenon in healthy rats, it could be explained in two ways. Namely, the bloodstream cells in the bone marrow pass into the circulation through the vascular sinus which represents the barrier between hematopoietic cells and blood. The wall of the vascular sinus in the bone marrow is coated with a continuous endothelial layer, while the outer surface of the endothelium is covered with a discontinuous layer of adventitial cells. In experimentally induced conditions such as acute blood loss, the adventitial cells are moving to the endothelium, allowing quick blood cell passage. Otherwise, megakaryocytes are located close to these sinuses and do not move to facilitate the passage of cells into the circulation. It is possible that the passing cells could be trapped into the megakaryocytes (20).

Another explanation is that the cytoplasm of megakaryocytes is a "shelter" for normal granulocytes during adverse conditions in the bone marrow microenvironment (24). Other hypotheses suggest that emperipolesis is a consequence of simple movement and adhesion of cells to megakaryocytes. When considering all the claims and hypotheses, previous studies have reported that emperipolesis is associated with rats age or is the result of accidental cell intake during migration into the bloodstream. Nevertheless, incidences of emperipolesis in previous studies are quite low in comparison to our results. Overall, emperipoletic megakaryocytes were present in all healthy rats, where the emperipoletic megakaryocytes/ megakaryocytes ratio was high.

Since high incidence of emperipolesis in our study was demonstrated in healthy rats that were younger than rats observed in other studies, emperipolesis in megakaryocytes may be related with uncontrolled mating (inbreeding). Rats in our laboratory have been inbred for several generations and children of parent-child or sibling-sibling unions as well as cousin-cousin unions were presented. It has been already known that inbred individuals are more likely to show physical and health defects like lower birth rate, loss of immune system function, increased cardiovascular risks and genetic disorders $(25,26)$.

\section{CONCLUSION}

Emperipolesis has been obtained with incidence of $100 \%$ and there was no significant difference in its appearance in the femoral and sternal bone marrow. Mainly, this phenomenon was characteristic of more differentiated cells of the megakaryocytic lineage. Interestingly, our animals were quite young; however, emperipolesis is a feature typical for older rats. In our case, over time, inbreeding within the rat population resulted in increased genetic relatedness between breeding individuals, so the incidence of emperipolesis is much higher than in cases of individuals who have not been bred in kinship.

\section{CONFLICT OF INTEREST STATEMENT}

The authors declared that they have no potential conflict of interest with respect to the authorship and/or publication of this article.

\section{REFERENCES}

1. Gupta, N., Jadhav, K., Shah, V. (2017). Emperipolesis, entosis and cell cannibalism: Demystifying the cloud. J Oral Maxillofac Pathol. 21 (1):92-98. https://doi.org/10.4103/0973-029X.203763 PMid:28479694 PMCid:PMC5406827 
2. Raja, H., Subramanyam, S.G., Govindaraj, S., Babu, M.K. (2011). A rare cause of massive lymphadenopathy. Indian J Surg Oncol. 2 (3): 212-214. https://doi.org/10.1007/s13193-011-0102-6 PMid:22942615 PMCid:PMC3272174

3. Sable, M.N., Sehgal, K., Gadage, V.S., Subramanian, P.G., Gujral, S. (2009). Megakaryocytic emperipolesis: A histological finding in myelodysplastic syndrome. Indian $\mathrm{J}$ Pathol Microbiol. 52, 599-600.

https://doi.org/10.4103/0377-4929.56153

PMid:19805998

4. Rastogi, V., Sharma, R., Misra, S.R., Yadav, L., Sharma, V. (2014). Emperipolesis - A Review. J Clin Diagn Res. 8 (12): ZM01-ZM02. https://doi.org/10.7860/JCDR/2014/10361.5299

5. Amita, K., Vijay Shankar, S., Abhishekh, M.G., Geethalakshmi, U. (2011). Emperipolesis in a case of adult $\mathrm{T}$ cell lymphoblastic lymphoma (mediastinal type) - Detected at FNAC and imprint cytology. Online J Health Allied Sci. 10, 11.

6. Vemuganti, G.K., Naik, M.N., Honavar, S.G. (2008). Rosaidorfman disease of the orbit. J Hematol Oncol. 1,7 . https://doi.org/10.1186/1756-8722-1-7 PMid:18588698 PMCid:PMC2474646

7. Lee, W.B., Erm, S.K., Kim, K.Y., Becker, R.P. (1999). Emperipolesis of erythroblasts within Kupffer cells during hepatic hemopoiesis in human fetus. Anat Rec. 256, 158-164.

https://doi.org/10.1002/(SICI)1097-0185 (19991001)256:2<158::AID-AR6>3.0.CO;2-0

8. Dziecioł, J., Lemancewicz, D., Kłoczko, J., Bogusłowicz, W., Lebelt, A. (2001). Megakaryocytes emperipolesis in bone marrow of the patients with non-Hodgkin's lymphoma. Folia Histochem Cytobiol. 2 (39):142-143.

9. Poppema, S. (1978). Sternberg-Reed cells with intracytoplasmic lymphocytes. Phagocytosis or emperipolesis? Virchows Arch A Pathol Anat Histol. 380, 355-359.

https://doi.org/10.1007/BF00431321

PMid:153049

10. Xia, P., Wang, S., Guo, Z., Yao, X. (2008). Emperipolesis, entosis and beyond: Dance with fate. Cell Res. 18, 705-707. https://doi.org/10.1038/cr.2008.64 PMid:18521104
11. Sierro, F., Tay, S.S., Warren, A., Le Couteur, D.G., McCaughan, G.W., Bowen, D.G., Bertolino, P. (2015). Suicidal emperipolesis: a process leading to cell-in-cell structures, T cell clearance and immune homeostasis. Curr Mol Med. 15 (9):819-827. https://doi.org/10.2174/1566524015666151026102143 PMid:26511707

12. Mansour, A., Abou-Ezzi, G., Sitnicka, E., Jacobsen, S.E.W., Wakkach, A., Blin-Wakkach, C. (2012). Osteoclasts promote the formation of hematopoietic stem cell niches in the bone marrow. J Exp Med. 209 (3):537-549.

https://doi.org/10.1084/jem.20110994

PMid:22351931 PMCid:PMC3302238

13. Arai, F., Hirao, A., Ohmura, M., Sato, H., Matsuoka, S., Takubo, K., Ito, K., Koh, G.Y., Suda, T. (2004). Tie2/angiopoietin-1 signaling regulates hematopoietic stem cell quiescence in the bone marrow niche. Cell. 118 (2): 149-161.

https://doi.org/10.1016/j.cell.2004.07.004 PMid:15260986

14. Kunisaki, Y., Bruns, I., Scheiermann, C., Ahmed, J., Pinho, S., Zhang, D., Mizoguchi, T., Wei, Q., Lucas, D., Ito, K., Mar, J.C., Bergman, A., Frenette, P.S. (2013). Nature. 502 (7473): 637-643.

https://doi.org/10.1038/nature12612 PMid:24107994 PMCid:PMC3821873

15. Becker, R.P., De Bruyn, P.P. (1976). The transmural passage of blood cells into myeloid sinusoids and the entry of platelets into the sinusoidal circulation; a scanning electron microscopic investigation. Am J Anat. 145 (2):183-205.

https://doi.org/10.1002/aja.1001450204 PMid:1258805

16. Heazlewood, S.Y., Neaves, R.J., Williams, B., Haylock, D.N., Adams, T.E., Nilsson, S.K. (2013). Megakaryocytes co-localise with hemopoietic stem cells and release cytokines that up-regulate stem cell proliferation. Stem Cell Res. 11 (2):782-792. https://doi.org/10.1016/j.scr.2013.05.007 PMid:23792434

17. Hartwig, J., Italiano, J. (2003). The birth of the platelet. J Thromb Haemost. 1 (7):1580-1586. https://doi.org/10.1046/j.1538-7836.2003.00331.x PMid:12871294

18. Shivdasani, R.A., Fujiwara, Y., McDevitt, M.A., Orkin, S.H. (1997). A lineage-selective knockout establishes the critical role of transcription factor GATA-1 in megakaryocyte growth and platelet development. EMBO J. 16 (13): 3965-3973. https://doi.org/10.1093/emboj/16.13.3965 PMid:9233806 PMCid:PMC1170020 
19. Rozman, C., Vives-Corrons, J.L. (1981). On the alleged diagnostic significance of megakaryocytic "phagocytosis" (emperipolesis). Br J Haematol. 48, 510. https://doi.org/10.1111/j.1365-2141.1981.tb02745.x PMid:7196253

20. Tavassoli, M. (1986). Modulation of megakaryocyte emperipolesis by phlebotomy: Megakaryocytes as a component of marrow-blood barrier. Blood Cells. 12, 205-216.

PMid:3790733

21. Centurione, L., Di Baldassarre, A., Zingariello, M., Bosco, D., Gatta, V., Rana, R.A., Langella, V., Di Virgilio, A., Vannucchi, A.M., Migliaccio, A.R. (2004). Increased and pathologic emperipolesis of neutrophils within megakaryocytes associated with marrow fibrosis in GATA-1(low) mice. Blood 104 (12):3573-3580.

https://doi.org/10.1182/blood-2004-01-0193

PMid:15292068

22. Lee, K.P. (1989). Emperipolesis of hematopoietic cells within megakaryocytes in bone marrow of the rat. Vet Pathol. 26, 473-478.

https://doi.org/10.1177/030098588902600603

PMid:2603328
23. Bobik, R., Dabrowski, Z. (1995). Emperipolesis of marrow cells within megakaryocytes in the bone marrow of sublethally irradiated mice. Ann Hematol. 70 (2):91-95.

https://doi.org/10.1007/BF01834387

PMid:7880931

24. De Pasquale, A., Paterlini, P., Quaglino, D., Quaglino, D. (1985). Emperipolesis ofgranulocytes within megakaryocytes. Br J Haematol. 60, 384-386. https://doi.org/10.1111/j.1365-2141.1985.tb07429.x PMid:3859322

25. Faree, M., Afzal, M. (2014). Evidence of inbreeding depression on height, weight, and body mass index: a population-based child cohort. Am J Hum Biol. 26 (6):784-795.

https://doi.org/10.1002/ajhb.22599

PMid:25130378

26. van Den Brandt, J., Kovács, P., Klöting, I. (2000). Metabolic variability among disease-resistant inbred rat strains and in comparison with wild rats (Rattus norvegicus). Clin Exp Pharmacol Physiol. 27 (10):793-795.

https://doi.org/10.1046/j.1440-1681.2000.03336.x PMid:11022971 